\title{
Comparative study of Negative Pressure Wound therapy Vs. Local antibiotic cream dressings in acute hand burns second-degree superficial to deep
}

\author{
Dr.Ganesh Chaudhari ${ }^{1}$, Dr. Satish Sonawane ${ }^{2}$
}

\author{
${ }^{1}$ MS, M.Ch. Plastic Surgery, Associate Professor, Department of Surgery, Dr.Vasantrao Pawar Medical College, Adgaon, \\ Nashik, Maharashtra, India \\ ${ }^{2}$ Professor, Department of Surgery, DVVPF’s Medical College, Ahmednagar, Maharashtra, India
}

\begin{abstract}
Background: The hand is one of the most common parts of the body involved in burns, i.e., $80 \%$. Even minor burns in the hand may result in severe limitations of function. Early initiation of physiotherapy, topical antibiotic cream treatment, collagen application, splintage, passive exercise for second-degree superficial burns. Materials and methods: A prospective comparative study was conducted in 10 patients with acute hand burns due to thermal burns (scald, flame). All patients with second-degree superficial to intermediate thickness burns were given Negative pressure wound therapy (indigenous NPWT Kit) to one hand and local antibiotic cream to the other hand or other parts of the body to study clinical profile and outcome. Results: A total of 10 patients were studied. The majority of patients were in 19 to 30 years of age group 6 patients $(60 \%)$, five females, and one male. Pediatric patients account for 4 patients $(40 \%)$, two female and two male children. Incidence of burns in females $70 \%$ and males' group 30\%. Significant reduction in postburn edema in NPWT hand compared to topical antibiotic cream dressing. Healing is fast in NPWT applied hand/part. Conclusion: Negative Pressure Wound Therapy for Acute second-degree superficial burns showed promising results in wound healing and reduced post-burn edema burn in hand in our study.
\end{abstract}

KEYWORDS: Negative Pressure Wound therapy; Indigenous; Acute second-degree superficial burns.

\section{INTRODUCTION}

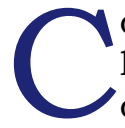
onventional management of Acute thermal hand burns is dressing with the application of local antibiotic creams, splinting, and hand elevation. NPWT is known for its ability to enhance wound healing [1]. We compare the conventional treatment with Negative Pressure Wound Therapy (using indigenous NPWT kit) splinting and hand elevation in second degree (superficial, intermediate) hand burns in the same extremity if it is involved apart from burned hand and other hands.

Thermal injury leads to two different types of injuries within the burn wound. First, an immediate and irreversible injury, and second, a delayed and partly reversible injury [2]. It is a ubiquitous observation in burned patients that areas that initially seemed to be partial-thickness burns must be regarded as total thickness within the next day or days. The impairment of blood flow within the zone of stasis is due to the impairment of the vascular patency at the microvascular level. This progression is closely correlated to the degree of oedema formation [2].

This study aims to compare its effectiveness against conventional treatment protocol for burn wounds. Controlled Negative pressure is helpful to prevent the progression of partial-thickness burn injuries $[3,4]$. The relatively more injured hand was treated with NPWT; less injured hand conservatively using silver sulphadiazine cream. In NPWT, a massive hyperperfusion was observed, being a possible reason for preventing burn progression [5, 6]. A significant amount of fluid was removed from the burn wound,

Correspondence: Dr. Ganesh Chaudhari, Plastic surgery, Associate professor Department of Surgery, Dr.Vasantrao Pawar Medical College, Adgaon, Nashik, Maharashtra, India Email: drganeshchaudhari76@gmail.com 
and a clinically obvious oedema reduction was observed compared to the contralateral side. We used locally available materials to reduce the cost of treatment effectively.

\section{Material And Methodology}

Study design: Prospective analytical study.

Ethical approval: The institutional ethics committee approved the study, and informed consent was ossssbtained from the participants.

Study place: SCL Hospital, Ahmedabad

Study duration: 2 years

Study population: Five adult females and one adult male age range 19 years to 38 years and four children with second degree superficial thickness 10 Acute hand burns.

\section{Sample size: Ten patients}

Inclusion criteria: Second-degree superficial burns, preferably bilateral upper extremity, Second-degree superficial + Second-degree deep (mix pattern), total burns percentage of burns less than or equal to $20 \%$ of Scald burns, or Flame burns.

Exclusion criteria: Electrical burns, Chemical burns, Radiation burns, Total second-degree deep burns, Third-degree burns/ full-thickness burns, Total Burns surface area more than $20 \%$.

Methodology: In the current study, done by using Negative Pressure Wound Therapy (NPWT) on the one hand and conventional dressing (CD) daily on the other hand and which include antibiotic creams (silver sulfadiazine) and splinting [7]. Compared the parameters clinically in terms of reduction of edema, comfort (in terms of pain) by visual analog scale while dressing, range of motion after each dressing, infection rate (in terms of local pus discharge and erythema), and healing rate over initial ten to fifteen days postburn on same extremity and other hands.

Indigenous NPWT Kit contains a Sterile piece of mattress foam thickness $2.5 \mathrm{~cm}$. (size cut according to the size of patient's hand, usually in adults, it is $20 \mathrm{~cm} \mathrm{X} 10 \mathrm{~cm}$, sterile suction catheter 12 to 14 French, plastic drape, piece of paraffin gauze, adhesive tape and Suction machine with pressure adjustment gauze. (Fig 1)

NPWT Application technique: After debridement of burned surface area and cleansing it with normal saline and dilute povidone-iodine solution, the burned surface of the hand is covered with sterile Paraffin gauze. Then assembled NPWT KIT is applied over gauze covering burned area. This assembly is sealed with a sterile plastic drape, taking care of the leakage by applying adhesive tape to create desired negative pressure. Splintage is given in an available position after this procedure. The catheter of the NPWT Kit is connected to a suction machine dedicated for NPWT or central suction available bedside. Negative pressure maintained between $80-125 \mathrm{~mm}$ Hg. NPWT application cycle is for 60 minutes with 5 minutes of relaxation for 2 - 3 days. During night hours, negative suction (midnight to $6.00 \mathrm{am}$ ) avoided. NWPT dressing changed at 2-3 days interval. Help \& the Cooperation of relatives is essential [8].

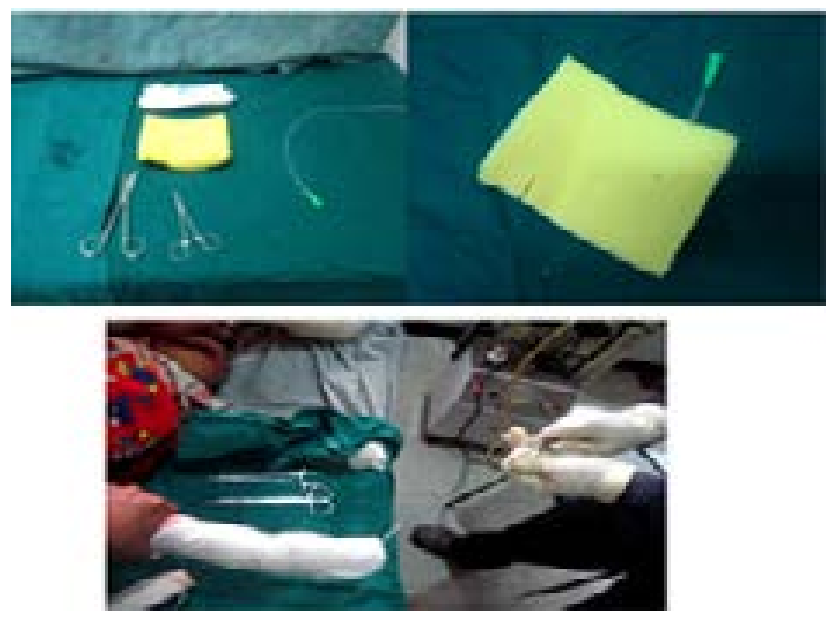

Fig 1. Material for NPWT Kit \& application

\section{RESUlts}

Table 1. Patients Data

\begin{tabular}{|l|l|l|l|l|l|l|l|l|}
\hline A & S & \multirow{2}{*}{$\begin{array}{c}\text { Type } \\
\text { e }\end{array}$} & e & \multicolumn{2}{|c|}{$\begin{array}{c}\text { Degree of Burns } \\
\text { e }\end{array}$} & \multicolumn{2}{|c|}{$\begin{array}{c}\text { Percentage } \\
\text { of burns }\end{array}$} & \multicolumn{2}{|c|}{$\begin{array}{c}\text { Modality of } \\
\text { treatment }\end{array}$} \\
\cline { 5 - 10 } & burns & RUE & LUE & RUE & LUE & RUE & LUE \\
\hline 4 & F & Scald & SS +SD & SS & 4 & 3 & NPWT & CD \\
\hline 30 & F & Scald & SS & SS+SD & 3 & 3 & CD & NPWT \\
\hline 6 & M & Scald & SS & SS & 4 & 3 & NPWT & CD \\
\hline 21 & F & Scald & SS & SS+SD & 5 & 4 & NPWT & CD \\
\hline 38 & F & Flame & SS+SD & SS+SD & 6 & 3 & NPWT & CD \\
\hline 7 & M & Scald & SS & SS & 4 & 4 & CD & NPWT \\
\hline 29 & F & Flame & SS+SD & SS & 3 & 4 & CD & NPWT \\
\hline 6 & F & Scald & SS & SS & 3 & 2 & NPWT & CD \\
\hline 34 & F & Scald & SS & SS & 5 & 4 & CD & NPWT \\
\hline 17 & M & Flame & SS+SD & SS+SD & 6 & 3 & NPWT & CD \\
\hline
\end{tabular}

SS- second-degree superficial, SD - Second degree profound, SS+SD- Mixed pattern, NPWT- Negative Pressure Wound Therapy, CD- Conventional Dressing.

Out of six adult patients, 5 were females and 1 male, age range 19 years-38years in 6 adults. In the pediatric group of 4 children, age range from 4 years to 7 years, 2 females and 2 males children. So $70 \%$ females and $30 \%$ males. Scald burns were seen in $7(70 \%)$ cases, and flame burns in $30 \%$. All cases show a significant reduction in edema in NPWT hands by day five in all patients except one female with flame burns in which edema was there till postburn day 10 . The average edema reduction time in NPWT was 5.7 days, and in $\mathrm{CD}$ was 6.4 days. The dynamic

Int. j. clin. biomed. res. 2020;6(2):28-32 
range of motions is more manageable after an initial period of stiffness in NPWT Hand; a passive range of motion is almost comparable in both. Several dressings more minor in NPWT treated hand burns, so decrease dressingrelated pain. The average VAS was 3 in NPWT and 6 in CD. Maceration is more in conventional dressings if silver sulfadiazine is used. Mild pus discharge was observed in a 4-year female child with flame burns. Healing was significantly fast in 9 out of 10 patients with NPWT. The average healing time for NPWT was 8 days and 9.3 days. So NPWT has a slightly rapid healing time than the CD. They were healing in terms of complete epithelialization of the wound without any raw area.

Table 2. Recorded Clinical Parameter

\begin{tabular}{|l|l|l|l|l|l|l|}
\hline Pateint & \multicolumn{2}{|l|}{$\begin{array}{l}\text { Edema } \\
\text { Reduction in } \\
\text { days }\end{array}$} & \multicolumn{2}{l|}{$\begin{array}{l}\text { Discomfort/ } \\
\text { pain by VAS }\end{array}$} & \multicolumn{2}{l|}{ Healing in days } \\
\hline & NPWT & CD & NPWT & CD & NPWT & CD \\
\hline 1 & 5 & 6 & 4 & 6 & 7 & 10 \\
\hline 2 & 5 & 6 & 2 & 4 & 8 & 7 \\
\hline 3 & 5 & 7 & 2 & 6 & 8 & 10 \\
\hline 4 & 5 & 7 & 2 & 6 & 9 & 11 \\
\hline 5 & 5 & 6 & 2 & 6 & 9 & 9 \\
\hline 6 & 5 & 5 & 4 & 8 & 8 & 9 \\
\hline 7 & 10 & 7 & 2 & 6 & 10 & 8 \\
\hline 8 & 7 & 8 & 6 & 6 & 7 & 9 \\
\hline 9 & 5 & 6 & 2 & 6 & 8 & 10 \\
\hline 10 & 5 & 6 & 2 & 4 & 8 & 12 \\
\hline
\end{tabular}

NPWT - Negative Pressure Wound Therapy, CDConventional Dressing, VAS- Visual Analogue Score.

\section{Illustrating typical two cases of this study:}

Case 1: A 4-year female child sustained scald burns due to hot water affecting bilateral hands. They admitted on Day 1 of burn injury with $6 \%$ burns. After initial resuscitation, NPWT for the right hand and conventional dressing are given for the left hand. Protocol for NPWT and $\mathrm{CD}$ as described following. Edema reduction, discomfort/pain recorded by VAS Scale, Healing in days recorded. (Table 2), ( fig 3-7).

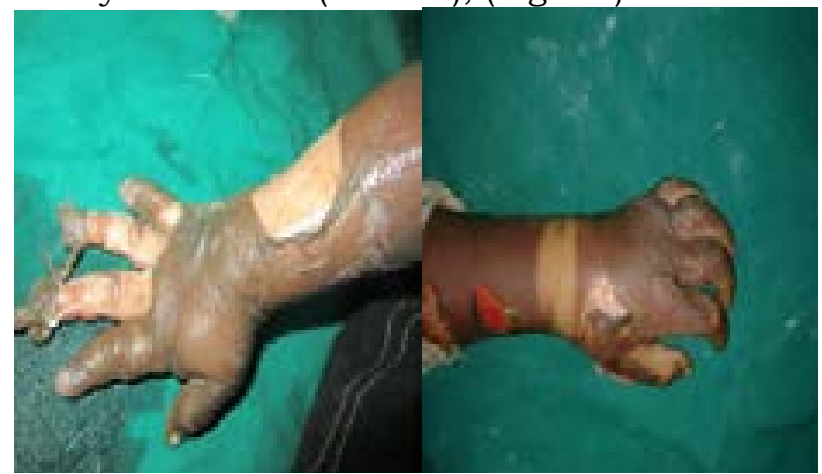

Fig 2. Day 1: Right Hand Burns Left Hand Burns

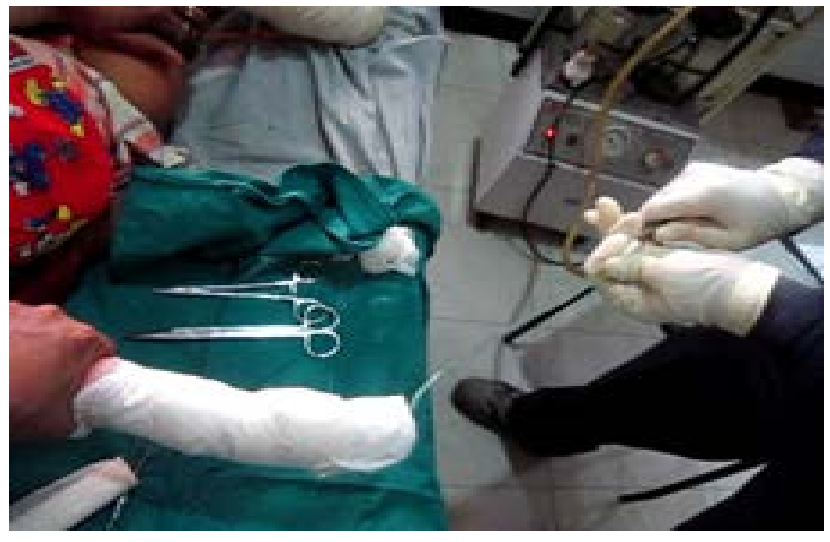

Fig 3. NPWT Application to Right hand
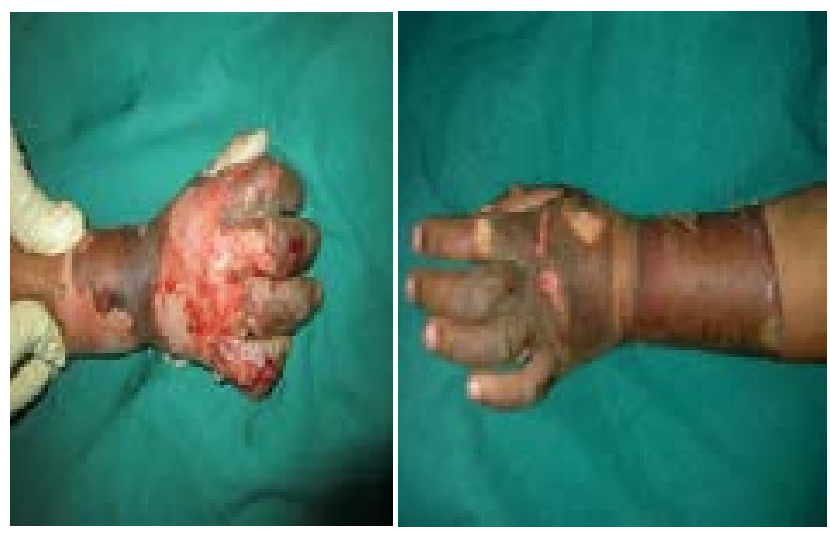

Fig 4. Day 3 status

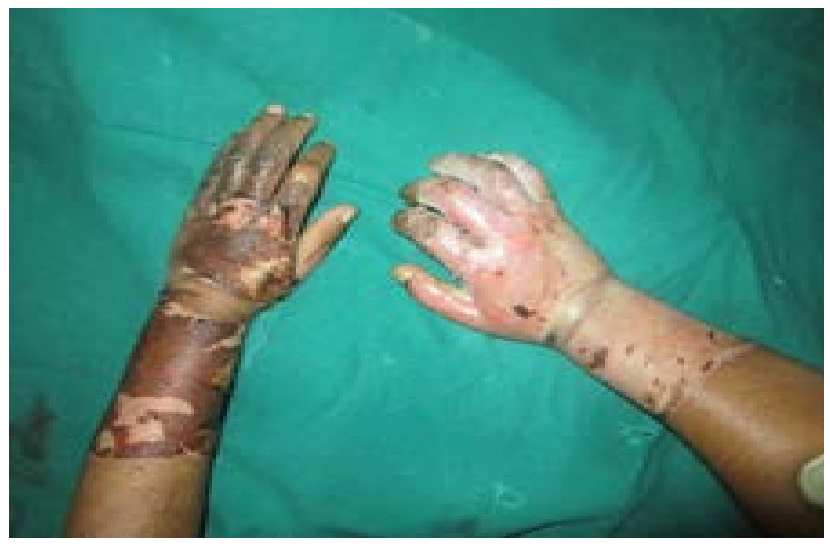

Fig 5. Day 5: Edema reduction

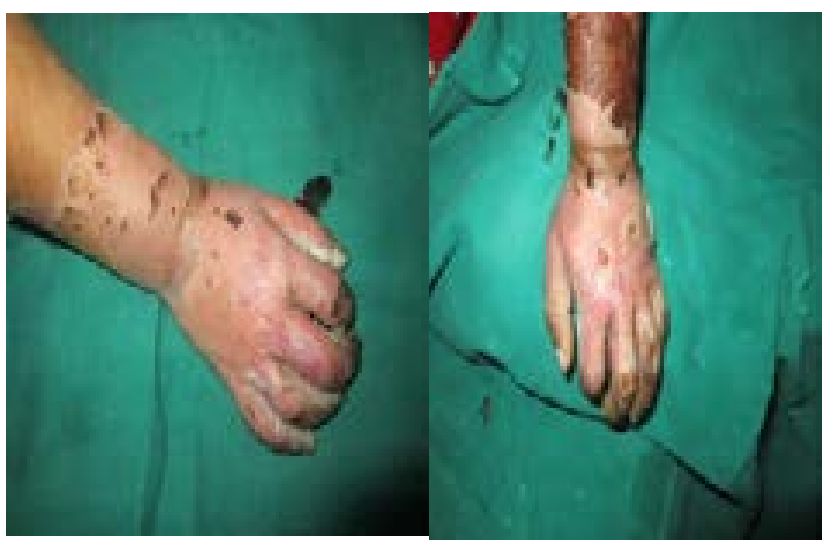

Fig 6. Day 7: Complete Epithelialization in NPWT

Int. j. clin. biomed. res. 2020;6(2):28-32 

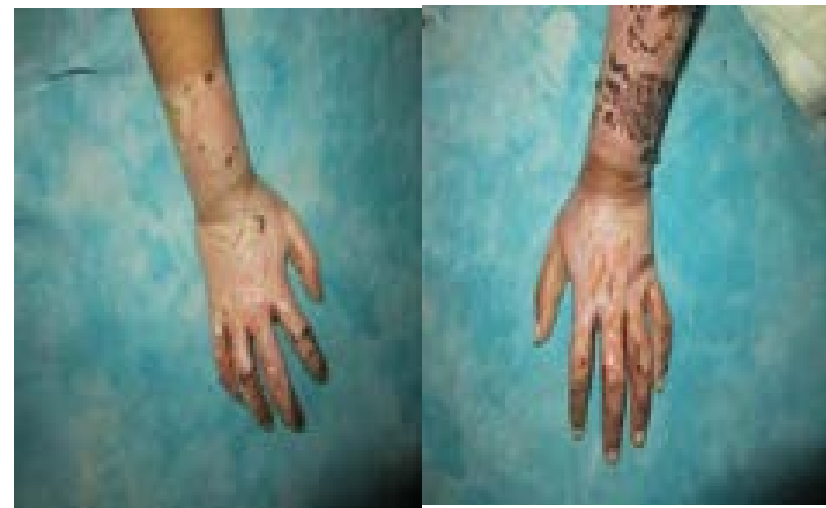

Fig 7. Day 9: Healed Right Hand, Some breach in epithelialization

Case 2 - A 30-year-old lady sustained bilateral hand burns due to spillage of hot milk. She had $3 \%$ burns on her right hand and forearm; $3 \%$ burns on her left and forearms. The right hand sustained second-degree superficial burns while the left hand and forearm sustained mixed patterns, i.e., second-degree superficial and deep burns. After initial resuscitation, NPWT for the left hand (mix pattern burns) and conventional dressing is given for the right hand. Protocol for NPWT and CD as described following. Edema reduction, discomfort/pain recorded by VAS Scale, Healing in days recorded. Although the left hand sustained mixed pattern burns, its healing due to NPWT application is comparable with the right hand, which had second-degree superficial burns. (Table 2), (Fig 8-11).

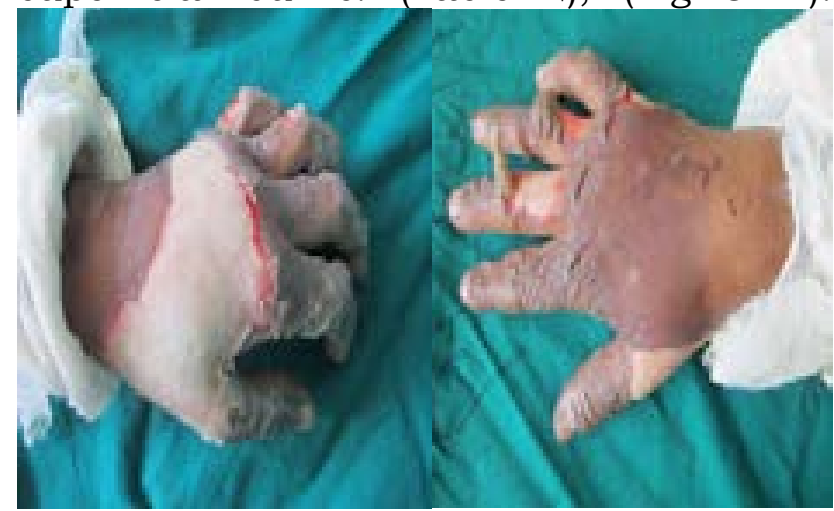

Fig 8. Day1: Left hand Mixed pattern burns (SS+SD) Right hand 20 superficial burns.

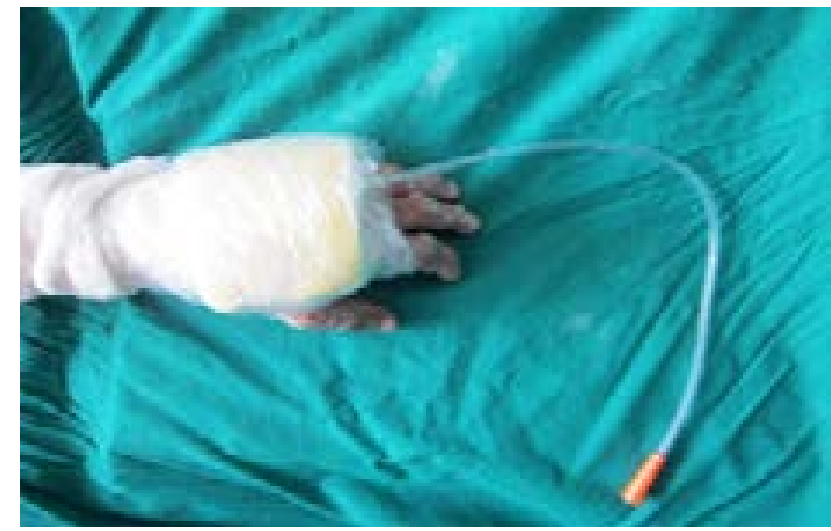

Fig 9. NPWT Application to left hand

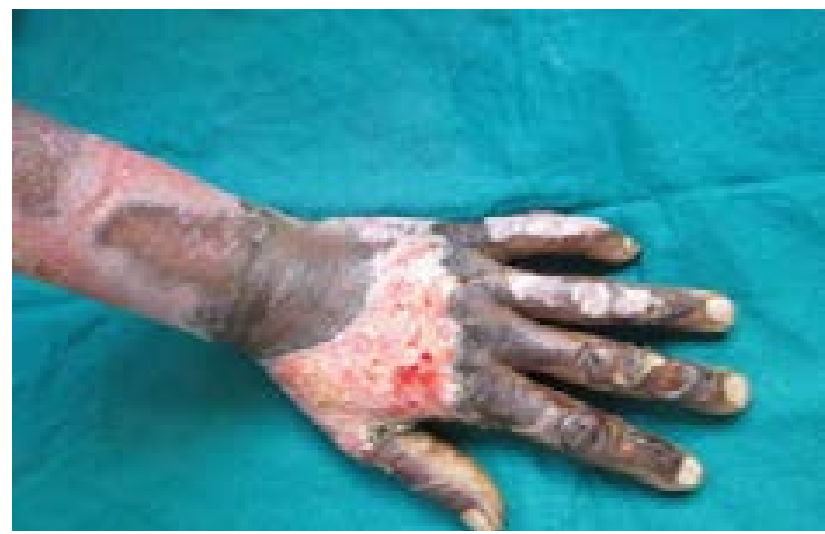

Fig 10. Day 5: Significant reduction in edema in NPWT hand.

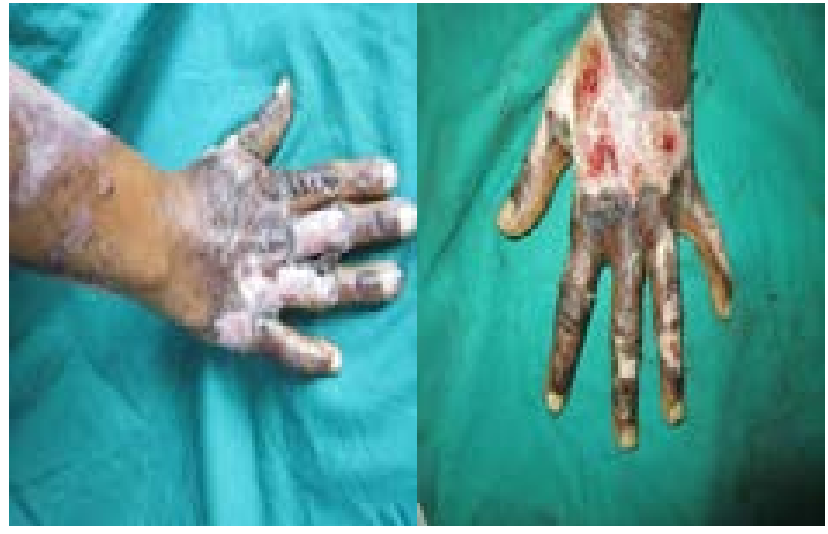

Fig 11. Day 7: Near total epithelialization in NPWT HAND

\section{Discussion}

The current treatment of acute hand burns is closed dressing with an antibiotic cream like silver-sulfadiazine, splint in antideformity position, hand elevation. Other equally effective options in second-degree superficial burns are an application of amnion, Collagen with splinting [9].

Our study used an indigenously made NPWT kit, which is much more economical than other dressings. Apart from maintaining closed \& moist dressing, intermittent negative pressure by NWPT is supposed to have a Leech effect, i.e., it prevents bacterial invasion, removes proinflammatory cytokines, and bacterial toxins along with wound secretions. The healing mechanism is based on the fact that NPWT exerts three-dimensional mechanical stress on the wound bed [10]. This is stress transmitted down to the cellular level, leading to activation of signal transduction pathways, which triggers cell recruitment, angiogenesis, growth factor expression, and cell proliferation [11].

Series of events that follow thermal injury frequently results in progressive loss of tissue. The concept of reversing this distinctive series of events has focused on the zone of stasis. Tissues in the zone of stasis that surround burn

Int. j. clin. biomed. res. 2020;6(2):28-32 
injuries usually die throughout 48 to 72 hours post-injury, resulting in a more severe injury. Application of a controlled sub-atmospheric pressure $(125 \mathrm{~mm} \mathrm{Hg})$ in an artificially closed space to partial-thickness burns in pigs significantly decreased the maximum depth of cellular death under the burn when the pressure was applied within 12 hours after burn creation (depth of control burns $=0.885+/-0.115 \mathrm{~mm}$; sub-atmospheric pressure treated burns $(0$-hour delay) $=0.095+/-0.025 \mathrm{~mm})[6,12]$. A decrease in the depth of cell death was noted when subatmospheric pressure was applied for as little as 6 hours. In summary, the application of the negative pressure to partial thickness burn injuries prevented the progression of the wound to a more profound injury in this experimental pig model. A 12-hour working window exists between injury and treatment with reduced pressure, with an application time of as little as 6 hours to successfully prevent injury progression.

In our study, all patients had second-degree superficial to intermediate thickness burns. Therefore, we selected intermediate thickness burns to superficial burns for NWPT. As a result, faster healing was observed in nine out of ten patients.

We found few drawbacks in NWPT, foul smell with each dressing change, inability to examine the affected hand during the treatment, and difficulty applying splint due to bulky dressing.

\section{Conclusion}

According to our study, patients with Seconddegree superficial to deep, i.e., mix pattern (partial thickness), may benefit from the application of NPWT by reducing oedema formation, increasing perfusion, and enhanced the rate of epithelialization. Our study is still in the initial stage. It requires more volume of cases. But still consider it one of the costeffective, viable options as we used indigenous NPWT Kit to treat second-degree superficial and deep Acute hand or extremity burns.

Conflict of interest : Nil

Source of funding : Nil

\section{REFERENCES}

1. Burns A Team Approach, Curtis Artz, John Moncrief, Basil prutt, 1979, Page 25- 26

2. Kamolz LP, Andel A, Haslik W, W Winter, Meissl G. Use of subatmospheric pressure therapy to prevent burn wound progression in human: first experiences. Burns. 2004;30(3):253-8
3. Morykwas MJ, David LR, Schnieder AM et al (1999) Use of subatmospheric pressure to prevent progression of partial-thickness burns in a swine model. J Burn Care Rehabil 20: 15-21 Pub med

4. Total burn care, David Herndon, 3rd Edition, page 127-135

5. Molnar JA. The use of a hypobaric device in acute human burns. 10th Annual Regional Burn Seminar, Chapel Hill, North Carolina. December. 1997; 6

6. Morykwas MJ, Argenta LC, Shelton-Brown EI et al (1997) Vacuum-assisted closure: a new method for wound control and treatment: animal studies and basic foundation. Ann Plast Surg 38:553-562

7. Marco Meloni, Valentina Izzo, Erika Vainieri, Laura Giurato, Valeria Ruotolo, and Luigi Uccioli. Management of negative pressure wound therapy in the treatment of diabetic foot ulcers, World J Orthop. 2015; 6(4): 387393.

8. Marek Kucharzewski, Paweł Mieszczański, Katarzyna Wilemska-Kucharzewska, Jakub Taradaj, Andrzej Kuropatnicki et al. The Application of Negative Pressure Wound Therapy in the Treatment of Chronic Venous Leg Ulceration: Authors Experience. Biomed Res Int. 2014; 297230.

9. Tianhong Dai, Ying-Ying Huang, Sulbha K. Sharma, Javad T. Hashmi, Divya B. Kurup, Michael R. HamblinTopical Antimicrobials for Burn Wound Infections. Recent Pat Antiinfect Drug Discov. 2010; 5(2): 124-151.

10. Panayi AC, Leavitt T, Orgill DP. Evidence based review of negative pressure wound therapy. World J Dermatol 2017; 6(1): 1-16

11. Effect of negative pressure wound therapy on wound healing, C. Huang et al. / Current Problems in Surgery 51 (2014) 301-33

12. Morykwas MJ, David LR, Schnieder AM et al (1999) Use of subatmospheric pressure to prevent progression of partial-thickness burns in a swine model. J Burn Care Rehabil 20: $15-21$

Int. j. clin. biomed. res. 2020;6(2):28-32 